\title{
Expression of miRNA-26a in platelets is associated with clopidogrel resistance following coronary stenting
}

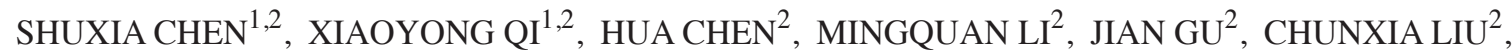

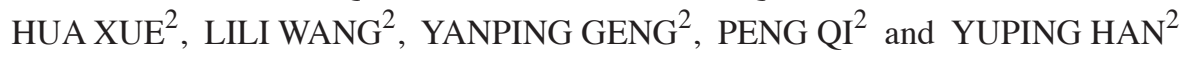 \\ ${ }^{1}$ Department of Internal Medicine, Hebei Medical University, Shijiazhuang, Hebei 050017; \\ ${ }^{2}$ Department of Cardiology, Hebei General Hospital, Shijiazhuang, Hebei 050051, P.R. China
}

Received January 24, 2015; Accepted March 8, 2016

DOI: $10.3892 / \mathrm{etm} .2016 .3278$

\begin{abstract}
The present study aimed to evaluate the association between platelet microRNA (miRNA)-26a expression and clopidogrel resistance in patients who underwent coronary stenting. Between September 2013 and August 2014, 43 patients with coronary heart disease underwent percutaneous coronary intervention at Heibei General Hospital (Shijiazhuang, China). In the same period, 20 healthy volunteers without any history of cardiovascular disease were enrolled in the present study as the control group. Flow cytometry was used to measure the phosphorylation levels of vasodilator-stimulated phosphoprotein (VASP), and to calculate the platelet reactivity index (PRI). Low response to clopidogrel was defined as PRI $\geq 50 \%$ on day 7 following clopidogrel administration. Western blotting was used to measure protein expression of VASP and reverse transcription-quantitative polymerase chain reaction analysis was performed to determine the expression levels of mRNA and miRNAs. Bioinformatics tools were employed to predict that miR-26a, miR-199 and miR-23a may target VASP mRNA. The results of the present study demonstrated that the activity of platelets in patients with low or high clopidogrel response was increased, as compared with healthy subjects. No differences in platelet VASP protein expression levels were detected between patients with high clopidogrel response and healthy subjects; whereas VASP protein expression was elevated in patients with low clopidogrel response. Furthermore VASP gene transcription was maintained at low levels in healthy subjects and patients with high clopidogrel response, whereas patients with low clopidogrel response exhibited increased VASP mRNA expression levels. Platelet expression of miRNA-26a, but not miRNA-199 or miRNA-23a, was associated with high platelet reactivity. Serum miRNA-26a, miRNA-199 and miRNA-23a were not demonstrated to be
\end{abstract}

Correspondence to: Dr Xiaoyong Qi, Department of Internal Medicine, Hebei Medical University, 361 Zhongshandong, Shijiazhuang, Hebei 050017, P.R. China

E-mail: hbghxy_q@163.com

Key words: vasodilator-stimulated phosphoprotein, clopidogrel resistance, microRNA, platelet, percutaneous coronary intervention involved in clopidogrel resistance. Therefore, the present study demonstrated that platelet miRNA-26a has an important role in clopidogrel resistance. Combined miRNA and VASP PRI tests may aid the early diagnosis and prediction of clopidogrel resistance.

\section{Introduction}

Clopidogrel is an antiplatelet drug which is the primary therapeutic agent used to treat patients with coronary atherosclerotic heart disease who have undergone percutaneous coronary intervention (PCI) or those with acute coronary syndrome $(1,2)$. As clopidogrel effectively reduces the incidence of stent thrombosis and significantly improves the prognosis of patients with coronary heart disease (CHD), it is one of the most important drugs for antiplatelet therapy following PCI (3). Previous studies have demonstrated that the effects of antiplatelet drugs are dependent on individual patients. Some patients, predominantly those who have received coronary stenting due to adverse cardiovascular events, experience recurring adverse cardiovascular events, despite taking adequate antiplatelet drugs such as long term clopidogrel $(4,5)$. It has been suggested that this is due to various factors, including clopidogrel resistance, which is attracting increasing concern (6). Clopidogrel resistance is associated with various factors, including individual differences between patients, interactions between drugs, polymorphisms in platelet genes, basic platelet reactivity and platelet sizes (7-9). However, the molecular mechanism underlying clopidogrel resistance remains unknown.

Clopidogrel is a type of adenosine diphosphate (ADP) receptor antagonist that belongs to the thienopyridine class of drugs. Following transformation by cytochrome P450, the active metabolites of clopidogrel irreversibly bind to the $\mathrm{P} 2 \mathrm{Y}_{12}$ ADP receptor on the surface of platelets and block the inhibition of cyclic adenosine monophosphate (cAMP) by inhibiting the binding sites of ADP, which promotes cAMP-dependent phosphorylation of proteins. Inhibition of the binding between fibrinogen and platelet glycoprotein GPIIb/IIIa receptor, and the subsequent deactivation of glycoprotein GPIIb/IIIa complexes inhibits the aggregation of platelets (10).

Vasodilator-stimulated phosphoprotein (VASP) is a type of intracellular actin regulatory protein, which is a reaction 
substrate for cAMP and cGMP-dependent protein kinase. Following stimulation, the $P 2 Y 12$ gene is capable of promoting the dephosphorylation of VASP. Clopidogrel suppresses the P2Y12 receptor, and inhibits the dephosphorylation of VASP. VASP phosphorylation levels can be determined using flow cytometry to determine the treatment efficacy of clopidogrel in patients $(11,12)$.

Previous studies have demonstrated that platelets exhibit high levels of microRNA (miRNA) expression $(13,14)$, which has an important role in the pathology of diseases associated with platelets $(15,16)$. However, few studies have investigated the effect of miRNA on clopidogrel resistance. Landry et al (17) have previously demonstrated that miR-223 regulates the expression of $\mathrm{P} 2 \mathrm{Y} 12$ receptor; whereas Kondkar et al (18) demonstrated that miR-96 has an important roles in the expression of vesicle-associated microtubule protein 8. Girardot et al (19) indicated that miR-28 directly regulates the thrombopoietin receptor gene. Currently, detection of VASP phosphorylation levels by flow cytometry is widely used for the investigation and clinical application of clopidogrel resistance (20). The present study investigated whether miRNAs in platelets are associated with clopidogrel resistance in patients with coronary heart disease following PCI. The combined miRNA and VASP platelet reactivity index tests performed in the present study may help with the early diagnosis and prediction of clopidogrel resistance.

\section{Materials and methods}

Patients. Between September 2013 and August 2014,43 patients with CHD underwent PCI surgery at Hebei General Hospital (Shijiazhuang, China). In the same time period, 20 healthy volunteers without any history of cardiovascular disease were enrolled in the present study as the control group. The following information was recorded for patients and healthy subjects: i) General clinical data, including gender, age, height, weight, blood pressure, platelet count, fasting plasma glucose level, liver function, kidney function, blood lipid level and plasma fibrinogen content; ii) CHD risk factors, including smoking, drinking, hypertension history and diabetes history; iii) anamnesis, including chronic hepatitis, chronic gastritis and thrombocytopenia; and iv) coronarography and PCI results.

Inclusion criteria for the patients with PCI were as follows: i) Aged between 45 and 80 years; ii) confirmed diagnosis of coronary atherosclerotic heart disease and planned stent implantation ( $\geq 70 \%$ target lesion stenosis, as indicated by coronarography). Exclusion criteria for patients with PCI were as follows: i) No significant stenosis or percutaneous coronary stent implantation contraindications; ii) severe heart failure, which was defined as left ventricular ejection fraction, $\leq 30 \%$; iii) severe liver-kidney dysfunction, which was defined as glutamic pyruvic transaminase or glutamic oxaloacetic transaminase, $\geq 80 \mu / 1$ and glomerular filtration rate, $\leq 125 \mathrm{ml} / \mathrm{min}$; iv) recent history of bleeding or heparin-induced thrombocytopenia; v) cerebrovascular disorder within 3 months; vi) major surgery within 1 month; vii) intake of clopidogrel 1 week prior to hospitalization; viii) life expectancy $<12$ months; and ix) allergy to aspirin, clopidogrel, heparin, stainless steel or contrast medium. All procedures were approved by the Ethics
Committee of Hebei General Hospital. Written informed consent was obtained from all patients or their families.

Platelet purification. Peripheral blood samples were supplemented with citrate dextrose, containing $85 \mathrm{mM}$ trisodium citrate, $78 \mathrm{mM}$ citric acid and $111 \mathrm{mM}$ glucose, and centrifuged at $80 \mathrm{x} \mathrm{g}$ for $10 \mathrm{~min}$ at $22^{\circ} \mathrm{C}$ to obtain the plasma. Following mixing with $2 \mathrm{mM}$ ethylenediaminetetraacetic acid, the platelet-rich plasma was centrifuged at $1,000 \mathrm{x}$ g for $10 \mathrm{~min}$ at $22^{\circ} \mathrm{C}$ to deposit the platelets. Subsequently, $3 \mathrm{ml}$ beads buffer, containing $0.8 \% \mathrm{NaCl}, 0.02 \% \mathrm{KCl}, 0.144 \% \mathrm{Na}_{2} \mathrm{HPO}_{4}, 0.024 \%$ $\mathrm{KH}_{2} \mathrm{PO}_{4}, 0.5 \%$ bovine serum albumin and $2 \mathrm{mM}$ ethylenediaminetetraacetic acid, was added to resuspend the platelets prior to the addition of $40 \mu \mathrm{l}$ human CD45 MicroBeads reagent (Miltenyi Biotec GmbH, Bergisch Gladbach, Germany). Following incubation at room temperature for $45 \mathrm{~min}$ with gentle mixing, a MACS ${ }^{\circledR}$ bead separation system (Miltenyi Biotec $\mathrm{GmbH}$ ) was used to collect leukocyte-depleted platelets with purity $>99.99 \%$.

Bioinformatics. For bioinformatics analysis, miRWalk (http://zmf.umm.uni-heidelberg.de/apps/zmf/mirwalk2/), miR anda (http://www.microrna.org/microrna/home.do) and Targetscan (http://www.targetscan.org/) databases were used to analyze the 3'-UTR region of VASP mRNA. The results of the three databases were collectively used to predict the roles of miR-26a, miR-199 and miR-23a in the regulation of VASP expression (21).

Reverse transcription-quantitative polymerase chain reaction $(R T-q P C R)$. miRNA expression was detected using SYBR Green (Takara Biotechnology Co., Ltd., Dalian, China) RT-qPCR, with U6 gene as an internal reference for relative quantification. cDNA was synthesized from $1 \mu \mathrm{g}$ total RNA using an M-MLV Reverse Transcription System (Takara Biotechnology Co., Ltd.), according to the manufacturer's protocol. PCR was performed using a total reaction volume of $25 \mu \mathrm{l}$, composed of 12.5 $\mu$ S SYR Premix Ex Taq (Takara Biotechnology Co., Ltd.), $1 \mu$ l PCR forward primer, $1 \mu$ l Uni-miR qPCR primer, $2 \mu \mathrm{l}$ template, and $8.5 \mu \mathrm{l}$ double distilled $\mathrm{H}_{2} \mathrm{O}$. Primer sequences were as follows: miR-26a, 5'-CGCGCTTCAAGTAATCCA GG-3'; miR-23a, 5'-ATCACATTGCCAGGGATTTCC-3'; miR-199a, 5'-CCCAGTGTTCAGACTACCTGTTC-3'; and U6, 5'-ACGCAAATTCGTGAAGCGTT-3'. PCR amplification conditions were as follows: Initial denaturation at $95^{\circ} \mathrm{C}$ for $30 \mathrm{sec}$, followed by 40 cycles of denaturation at $95^{\circ} \mathrm{C}$ for $5 \mathrm{sec}$, and annealing at $60^{\circ} \mathrm{C}$ for $20 \mathrm{sec}$ (Veriti Dx Thermal Cycler; Thermo Fisher Scientific, Inc., Waltham, MA, USA). The $2^{-\Delta \Delta \mathrm{Cq}}$ method was used to calculate miRNA relative expression levels (22). Each sample was measured in triplicate.

mRNA was extracted using TRIzol reagent (Invitrogen; Thermo Fisher Scientific, Inc.), according to the manufacturer's protocol. SYBR Green (Takara Biotechnology Co., Ltd.) RT-qPCR was employed to determine the mRNA expression levels of VASP in platelets, using glyceraldehyde-3-phosphate dehydrogenase (GAPDH) as internal reference for quantification analysis. VASP mRNA reaction system was composed of $10 \mu \mathrm{l}$ SYBR Premix Ex Taq mix, $0.5 \mu 1$ upstream primer (5-'CAACTCAGGAGGAGCCAGAGG-3'), $0.5 \mu$ l downstream primer (5-'TCACCCTCTGTAGGTCCGAG-3'), $1 \mu \mathrm{l}$ cDNA 
Table I. Clinical characteristics of healthy subjects and patients with coronary heart disease who underwent coronary stenting.

\begin{tabular}{|c|c|c|c|}
\hline Characteristic & Control group & $\begin{array}{l}\text { Low clopidogrel response } \\
\text { group }(n=17)\end{array}$ & $\begin{array}{l}\text { High clopidogrel response } \\
\text { group }(n=26)\end{array}$ \\
\hline Female, n (\%) & $7(35)$ & $6(35.29)$ & $10(38.46)$ \\
\hline Age, years & $61.9 \pm 5.8$ & $62.8 \pm 6.9$ & $61.3 \pm 7.4$ \\
\hline Smoker, n (\%) & $8(40)$ & $7(41.17)$ & $9(34.61)$ \\
\hline Body mass index, $\mathrm{kg} / \mathrm{m}^{2}$ & $23.83 \pm 1.59$ & $24.97 \pm 2.23$ & $23.34 \pm 1.77$ \\
\hline Type II diabetes, n (\%) & 0 & $7(41.17)^{\mathrm{a}}$ & $11(42.31)^{\mathrm{a}}$ \\
\hline Hyperlipidemia, n (\%) & 0 & $7(41.18)^{\mathrm{a}}$ & $11(42.31)^{\mathrm{a}}$ \\
\hline Hypertension, n (\%) & 0 & $9(52.94)^{\mathrm{a}}$ & $14(53.85)^{\mathrm{a}}$ \\
\hline Fibrinogen content, $\mathrm{g} / \mathrm{l}$ & $2.87 \pm 0.53$ & $3.14 \pm 0.49^{\mathrm{a}}$ & $3.06 \pm 0.57^{\mathrm{a}}$ \\
\hline Platelet count, $10^{9} / 1$ & $200 \pm 75$ & $223 \pm 87$ & $219 \pm 79$ \\
\hline Left ventricular ejection fraction, $\%$ & $61 \pm 6.8$ & $53.5 \pm 11.6^{\mathrm{a}}$ & $54.3 \pm 10.8^{\mathrm{a}}$ \\
\hline
\end{tabular}

${ }^{\mathrm{a}} \mathrm{P}<0.05$ vs. the control group. Unless otherwise stated, data are expressed as the mean \pm standard deviation.

and $8 \mu \mathrm{l}$ double distilled $\mathrm{H}_{2} \mathrm{O}$. PCR amplification conditions were as follows: Initial denaturation at $95^{\circ} \mathrm{C}$ for $10 \mathrm{~min}$, followed by 40 cycles of denaturation at $95^{\circ} \mathrm{C}$ for $1 \mathrm{~min}$, annealing at $60^{\circ} \mathrm{C}$ for $40 \mathrm{sec}$ and elongation at $72^{\circ} \mathrm{C}$ for $30 \mathrm{sec}$, and final extension at $72^{\circ} \mathrm{C}$ for $1 \mathrm{~min}$. The $2^{-\Delta \Delta \mathrm{Cq}}$ method was used to calculate the relative expression of VASP mRNA (22). Each sample was tested in triplicate.

Western blotting. Platelets, which were purified from $5 \mathrm{ml}$ whole blood, were supplemented with $600 \mu \mathrm{l}$ precooled radioimmunoprecipitation assay lysis buffer, containing $50 \mathrm{mM}$ Tris-base, $1 \mathrm{mM}$ EDTA, $150 \mathrm{mM} \mathrm{NaCl}, 0.1 \%$ SDS, $1 \%$ Triton $\mathrm{X}-100$ and $1 \%$ sodium deoxycholate (Beyotime Institute of Biotechnology, Shanghai, China). Following lysis for $50 \mathrm{~min}$ on ice, the mixture was centrifuged at $12,000 \mathrm{x} \mathrm{g}$ for $5 \mathrm{~min}$ at $4{ }^{\circ} \mathrm{C}$. The supernatant was collected in order to determine protein concentration using a bicinchoninic acid protein concentration determination kit (RTP7102; Real-Times Biotechnology Co., Ltd., Beijing, China). Protein samples $(50 \mu \mathrm{g})$ were subsequently mixed with equal volumes of $2 \mathrm{X}$ sodium dodecyl sulfate loading buffer prior to denaturation in a boiling water bath for $5 \mathrm{~min}$. Protein samples $(10 \mu \mathrm{l})$ were separated by sodium dodecyl sulfate-polyacrylamide gel electrophoresis at $100 \mathrm{~V}$. Resolved proteins were transferred to polyvinylidene difluoride membranes on ice at $300 \mathrm{~mA}$ for $1.5 \mathrm{~h}$, and were subsequently blocked with $50 \mathrm{~g} / 1$ skimmed milk at room temperature for $1 \mathrm{~h}$. Subsequently, the membranes were incubated with polyclonal rabbit anti-goat VASP (1:5,000; cat. no. ab209093) and polyclonal rabbit anti-goat GAPDH primary antibodies (1:2,000; cat. no. ab37168) (Abcam, Cambridge, MA, USA) at $4^{\circ} \mathrm{C}$ overnight. Following washing three times with phosphate-buffered saline with Tween 20 (PBST) for $15 \mathrm{~min}$, the membranes were incubated with horseradish peroxidase-conjugated goat anti-rabbit secondary antibody (1:1,000; cat. no. ab6721; Abcam) for $1 \mathrm{~h}$ at room temperature. Following washing three times with PBST for 15 min, the membrane was developed using an enhanced chemiluminescence detection kit (Sigma-Aldrich, St. Louis, MO, USA). Image Lab software (verson 4.0; Bio-Rad Laboratories, Inc., Hercules, CA, USA) was used to acquire and analyze imaging signals. The relative content of VASP protein was expressed as a ratio of VASP/GAPDH.

Flow cytometry. Flow cytometry was used to measure the phosphorylation levels of VASP following stimulation with vasodilators, and to calculate the PRI. At least $6 \mathrm{~h}$ prior to surgery, patients were administered $300 \mathrm{mg}$ clopidogrel, and clopidogrel was maintained at $75 \mathrm{mg}$ daily following surgery. Seven days after clopidogrel administration, fasting blood samples $(4 \mathrm{ml})$ were collected from patients and tested within 48 haccording to the manufacturer's protocol(PLTVASP/P2Y12 kit; Diagnostica Stago S.A.S., Paris, France). Following count analysis using FACSCalibur (BD Biosciences, San Jose, CA, USA), the 'corrected' mean fluorescence intensity (MFI) values (MFIc) of tubes T1 and T2 were determined. MFIc was calculated from MFI values obtained from MAb anti-VASP-P (tubes T1 and T2) following subtraction of the negative controls (tube T3): MFIc (PGE1)=MFIc (T1)=MFI (T1) - MFI (T3); MFIc (PGE1 + ADP) $=$ MFIc (T2)=MFI (T2) - MFI (T3). PRI was calculated using the following function: $\mathrm{PRI}=[\mathrm{MFIc}$ (PGE1) - MFIc (PGE1 + ADP)]/MFIc (PGE1) x 100. At least one normal sample was tested as a control for each patient sample. Low response to clopidogrel was defined as PRI $\geq 50 \%$ on day 7 following administration, whereas high response was defined as PRI $<50 \%$ (23).

Statistical analysis. Student's t-tests were performed using SPSS 16.0 for Windows (SPSS, Inc., Chicago, IL, USA). All data were expressed as the mean \pm standard deviation. $\mathrm{P}<0.05$ was considered to indicate a statistically significant difference.

\section{Results}

Clinical data. Clinical data were collected from 43 patients and 20 healthy subjects (Table I). The data demonstrated that patients with low clopidogrel response were not significantly different from those with high clopidogrel response, according to all clinical data and postoperative cardiovascular physiological and biochemical indicators. In addition, healthy subjects were not significantly different from patients with low or high 


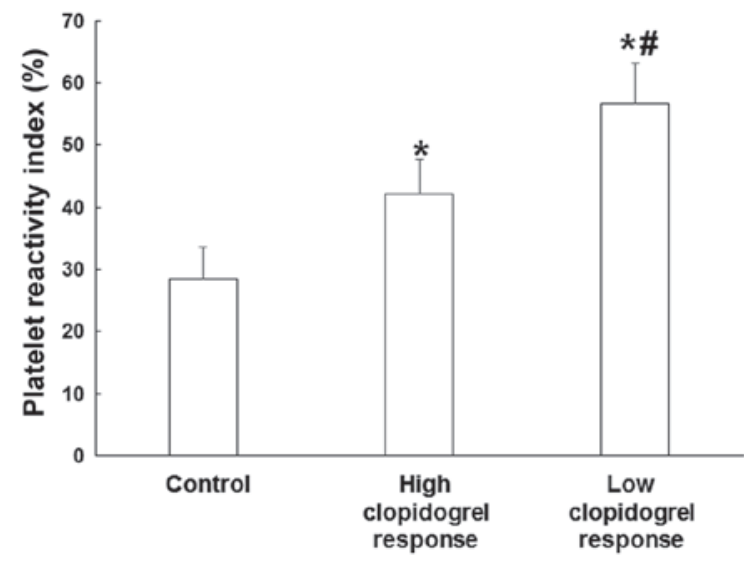

Figure 1. Platelet reactivity index (PRI). Flow cytometry was used to measure the phosphorylation levels of vasodilator-stimulated phosphoprotein following stimulation with vasodilators, and to calculate the PRI. Low response to clopidogrel was defined as PRI $\geq 50 \%$ on day 7 post-clopidogrel administration. Data are expressed as the mean \pm standard deviation. $\mathrm{P}<0.05$, vs. the control group; ${ }^{\#} \mathrm{P}<0.05$, vs. the low clopidogrel response group.

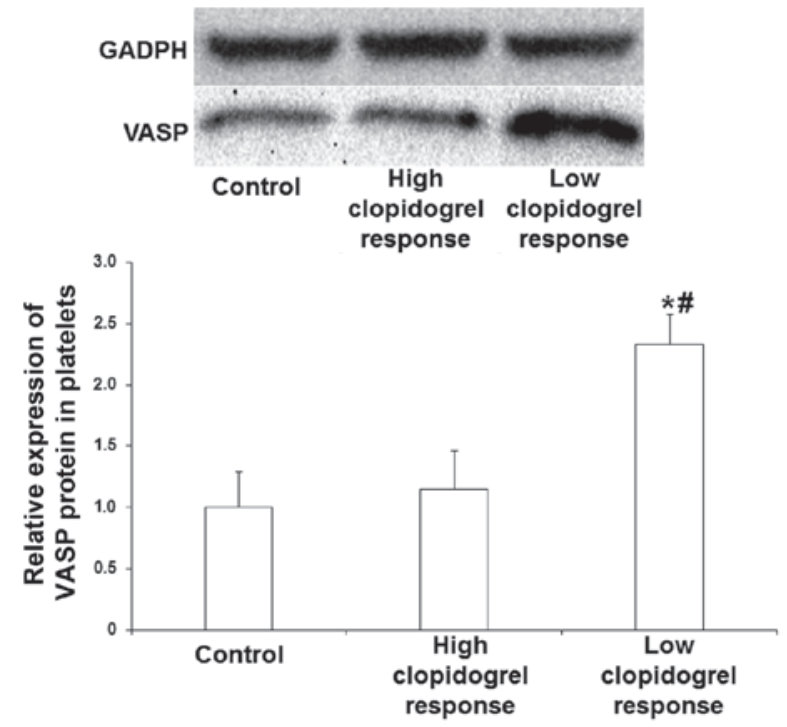

Figure 2. Relative expression of VASP protein in platelets, as detected by western blotting. The relative content of VASP protein was expressed as VASP/GAPDH ratio. Data are expressed as the mean \pm standard deviation. ${ }^{*} \mathrm{P}<0.05$, vs. the control group; ${ }^{\#} \mathrm{P}<0.05$, vs. the high clopidogrel response group. VASP, vasodilator-stimulated phosphoprotein.

clopidogrel response in gender, age, smoking, body mass index or platelet count. However, healthy subjects did not present with type II diabetes, hyperlipidemia or hypertension. Although still within the normal range, patients with low or high clopidogrel response exhibited significantly increased fibrinogen content, as compared with the healthy subjects $(\mathrm{P}<0.05)$. These results indicated that PCI may not significantly alter CHD risk factors, such as type II diabetes, hypertension and age, in patients with CHD.

Platelet activity increases in patients with low or high clopidogrel response. To calculate PRI, flow cytometry was performed to measure the phosphorylation levels of VASP. Analysis of the results demonstrated that the number of patients with low

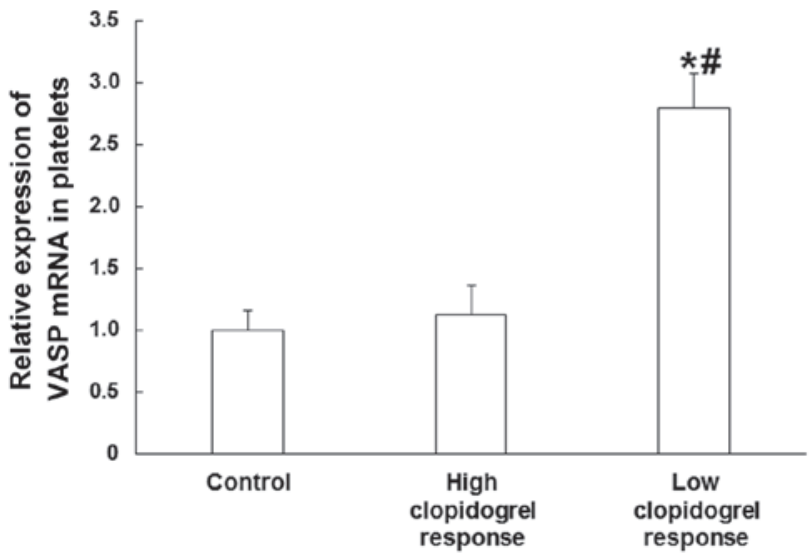

Figure 3. Relative expression of VASP mRNA in platelets, as detected by reverse transcription-quantitative polymerase chain reaction. GAPDH was used as an internal reference for quantification analysis. Data are expressed as the mean \pm standard deviation. ${ }^{*} \mathrm{P}<0.05$, vs. the control group; ${ }^{\#} \mathrm{P}<0.05$, vs. the high clopidogrel response group. VASP, vasodilator-stimulated phosphoprotein.

clopidogrel response (PRI $\geq 50 \%$ ) was 17 (39.53\%); whereas the number of patients with high clopidogrel response (PRI <50\%) was $26(60.47 \%)$. In addition, the average PRI values of patients with low response or normal response to clopidogrel were significantly higher, as compared with the healthy subjects $(\mathrm{P}<0.05)$. Notably, the average PRI of patients with low clopidogrel response was significantly increased, as compared with the high clopidogrel response group $(\mathrm{P}<0.05)$ (Fig. 1). These results suggested that platelet activity is increased in patients with low or high clopidogrel response, as compared with healthy subjects, on day 7 following clopidogrel treatment.

Platelet VASP protein expression is inhibited by clopidogrel in patients with high clopidogrel response, and elevated in patients with low clopidogrel response. Western blotting was performed to measure VASP protein expression in platelets. The results demonstrated that platelet VASP protein expression did not significantly differ between patients with high clopidogrel response and healthy subjects, whereas platelet VASP protein expression was significantly higher in patients with low clopidogrel response, as compared with healthy subjects and patients with high clopidogrel response $(\mathrm{P}<0.05)(\mathrm{Fig} .2)$. These results suggested that platelet VASP protein expression may be inhibited by clopidogrel in patients with high clopidogrel response, whereas VASP protein expression may be elevated in patients with low clopidogrel response, who may have high platelet reactivity.

VASP gene transcription is significantly increased in patients with low clopidogrel response. RT-qPCR was used to determine VASP mRNA expression levels in platelets. The results demonstrated that there was no significant difference between the platelet VASP mRNA expression levels of patients with high clopidogrel response and healthy subjects. However, patients with low clopidogrel response exhibited significantly increased platelet VASP mRNA expression levels, as compared with healthy subjects and patients with high clopidogrel response $(\mathrm{P}<0.05)$ (Fig. 3). These results indicated that VASP gene transcription is significantly increased in patients with low 
A

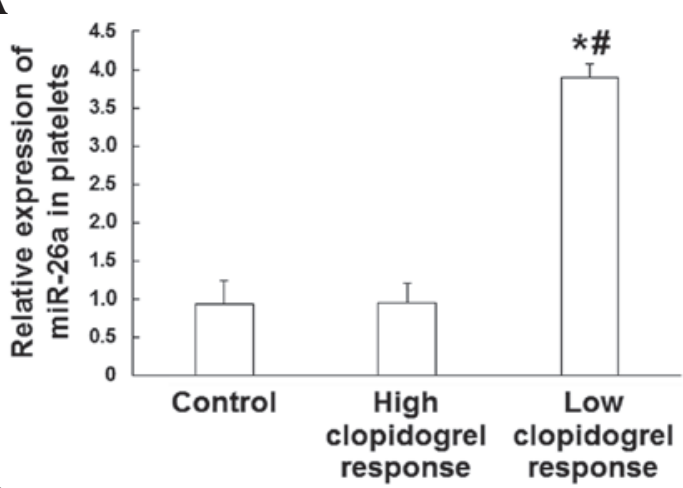

B
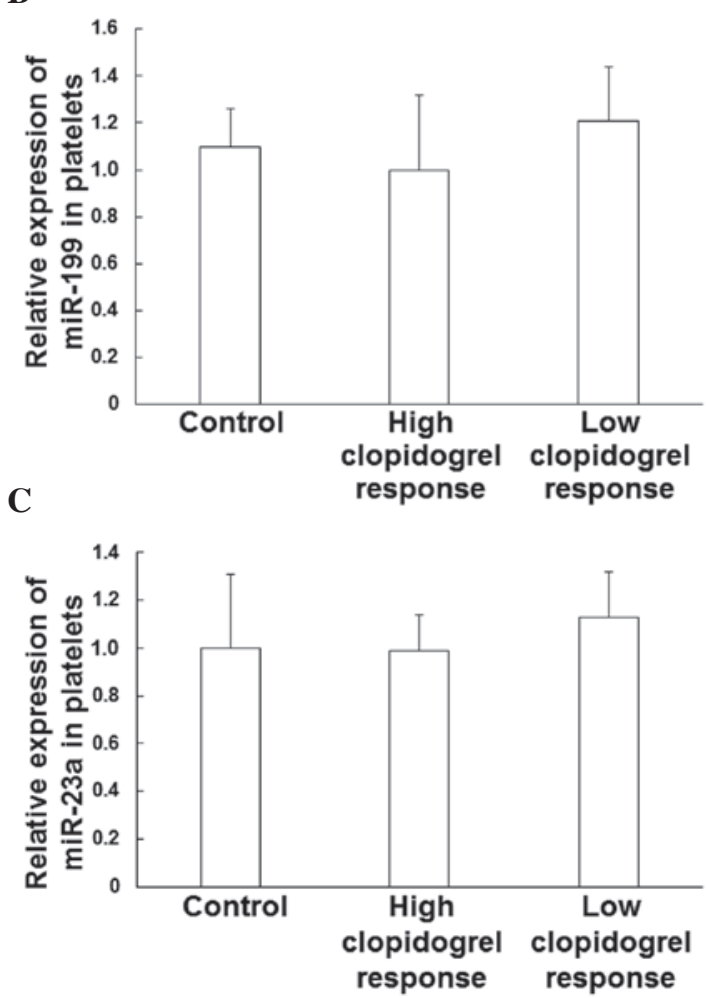

Figure 4. Relative expression levels of (A) miR-26a, (B) miR-199 and (C) miR-23a in platelets. miRNA expression was detected by reverse transcription-quantitative polymerase chain reaction with SYBR Green. U6 gene was used as an internal reference for relative quantification. Data are expressed as the mean \pm standard deviation. ${ }^{*} \mathrm{P}<0.05$, vs. the control group; ${ }^{\#} \mathrm{P}<0.05$, vs. the high clopidogrel response group.

clopidogrel response, as compared with healthy subjects and patients with high clopidogrel response, which exhibit similar low expression levels.

miR-26a expression is associated with high platelet reactivity. RT-qPCR was performed to determine whether miR-26a, miR-199 or miR-23a in platelets can target VASP mRNA. The results demonstrated that relative expression of platelet miR-26a in patients with low clopidogrel response was significantly increased, as compared with healthy subjects or patients with high clopidogrel response $(\mathrm{P}<0.05$; Fig. 4A); however, this phenomenon was not observed for either miR-199 or miR-23a (Fig. 4B and C). These results suggested that the expression of miR-26a in platelets may be associated with high platelet reactivity, whereas miR-199 and miR-23a are not.
A

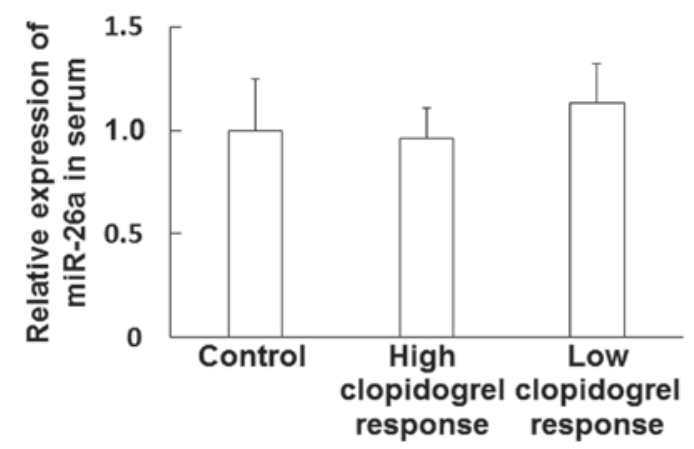

B

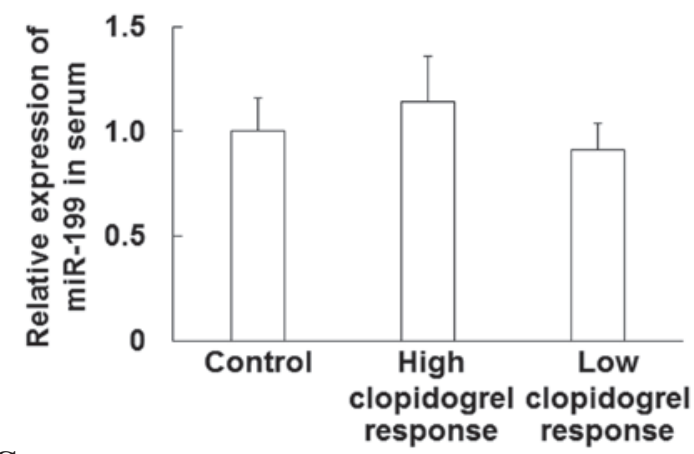

C

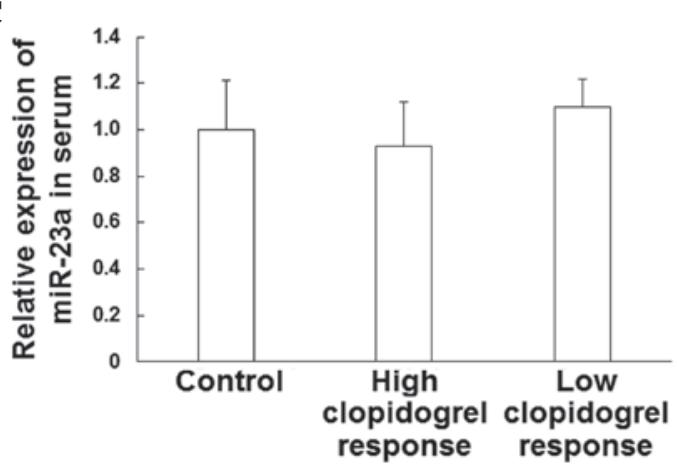

Figure 5. Relative expression levels of (A) miR-26a, (B) miR-199 and (C) miR-23a in serum. miRNA expression was detected by reverse transcription-quantitative polymerase chain reaction with SYBR Green. U6 gene was used as an internal reference for relative quantification. Data are expressed as the mean \pm standard deviation.

Serum miR-26a, miR-199 and miR-23a are not associated with clopidogrel resistance. To investigate whether serum miR-26a, miR-199 or miR-23a participate in clopidogrel resistance, their respective expression levels were measured using RT-qPCR. The results demonstrated that the serum expression levels of miR-26a, miR-199 and miR-23a did not differ among the three groups (Fig. 5A-C). These results indicated that serum miR-26a, miR-199 and miR-23a are not involved in clopidogrel resistance.

\section{Discussion}

Clopidogrel, which is as a derivative of thienopyridine with strong antiplatelet activity, has previously been demonstrated by large-scale clinical trials to reduce the occurrence of adverse cardiovascular events $(1,3)$. Although various studies have demonstrated clopidogrel resistance since its discovery in 
2003, the exact mechanism is yet to be elucidated (24-26). Flow cytometry has been used to detect platelet activity $(27,28)$, however clopidogrel resistance remains poorly defined. Furthermore, the association between clopidogrel resistance and adverse clinical events requires urgent investigation (29). In the present study, flow cytometry was used to calculate the PRI, in order to assess clopidogrel reactivity. As PRI was determined from the phosphorylation level of phosphoprotein, this method benefits from relatively increased sensitivity and specificity in defining clopidogrel resistance, compared with detecting clopidogrel resistance based on the ADP-induced change of platelet aggregation rate. VASP phosphorylation specificity reflects ADP receptor activity, thus avoiding the impact of platelet aggregation induced by arachidonic acid, thromboxane or fibrinogen (30). In the present study, low clopidogrel response was defined as PRI $\geq 50 \%$ (23). Among the 43 patients and 20 healthy subjects investigated, 17 cases exhibited VASP PRI $\geq 50 \%$ (39.53\% of patients following PCI) and 26 had VASP PRI $<50 \%$ (60.47\% of patients following PCI), with average PRI values of $56.53 \pm 2.68 \%$ and $42.15 \pm 5.08 \%$, respectively.

To date, research on clopidogrel resistance at the molecular level has predominantly focused on gene polymorphisms $(9,31,32)$, rather than associations with miRNA expression in platelets. Testing VASP phosphorylation is a reliable method for the detection of clopidogrel resistance, however it lacks early detection and indicators (20). Therefore, the present study focused on specific marker miRNAs in platelets that are associated with the occurrence and development of clopidogrel resistance. miRNAs are small non-coding RNAs (18-22 nucleotides) that are capable of regulating gene expression by interfering with transcription or inhibiting translation, hence miRNAs participate in the regulation of numerous biological signaling pathways. miRNAs can stably exist in the blood (plasma, platelets, red blood cells and nucleated blood cells) or urine, without being degraded by endogenous RNA polymerase (33). VASP is abundantly expressed in platelets is abundant and VASP phosphorylation levels have previously been demonstrated to define PRI (29). In the present study, the results of western blotting and RT-qPCR analysis demonstrated that the protein and mRNA expression levels of VASP in platelets were significantly increased in patients with low clopidogrel response. Therefore, we hypothesized that miRNA in platelets may participate in the regulation of VASP gene transcription. Bioinformatics analysis of the 3'-UTR region of VASP mRNA predicted that miR-26a, miR-199 and miR-23a may target VASP mRNA. Subsequent RT-qPCR analysis of the expression of miR-26a, miR-199 and miR-23a in platelets and serum demonstrated that only miR-26a expression in platelets was significantly elevated in patients with low clopidogrel response. No differences in serum expression of the three miRNAs were detected among the three groups. These results suggested that the expression of miR-26a in platelets is associated with high platelet reactivity, and miR-26a may participate in platelet reactivity regulation by clopidogrel via the regulation of VASP expression. However, due to the small sample number and the complexity and diversity of miRNA regulation mechanisms, the results of the present study have some limitations. Further experiments are required to investigate whether a direct regulation mechanism exists between miR-26a and VASP.
In conclusion, the results of the present study demonstrated that the expression of miR-26a in platelets has an important role in clopidogrel resistance. Combined miRNA and VASP PRI tests may aid the early diagnosis and prediction of clopidogrel resistance.

\section{Acknowledgements}

The present study was supported by the Research Projects Bureau of Traditional Chinese Medicine of Hebei Province (grant no. 2013028).

\section{References}

1. CAPRIE Steering Committee: A randomised, blinded, trial of clopidogrel versus aspirin in patients at risk of ischaemic events (CAPRIE). CAPRIE Steering Committee. Lancet 348: 1329-1339, 1996

2. Yusuf S, Zhao F, Mehta SR, Chrolavicius S, Tognoni G and Fox KK; Clopidogrel in Unstable Angina to Prevent Recurrent Events Trial Investigators: Effects of clopidogrel in addition to aspirin in patients with acute coronary syndromes without ST-segment elevation. N Engl J Med 345: 494-502, 2001.

3. Mehta SR, Yusuf S, Peters RJ, Bertrand ME, Lewis BS, Natarajan MK, Malmberg K, Rupprecht H, Zhao F, Chrolavicius S, et al: Effects of pretreatment with clopidogrel and aspirin followed by long-term therapy in patients undergoing percutaneous coronary intervention: The PCI-CURE study. Lancet 358: 527-533, 2001.

4. Kuliczkowski W, Witkowski A, Polonski L, Watala C, Filipiak K, Budaj A, Golanski J, Sitkiewicz D, Pregowski J, Gorski J, et al: Interindividual variability in the response to oral antiplatelet drugs: A position paper of the working group on antiplatelet drugs resistance appointed by the section of cardiovascular interventions of the polish cardiac society, endorsed by the workinggroup on thrombosis of the european society of cardiology. Eur Heart J 30: 426-435, 2009.

5. Angiolillo D J, Fernandez-Ortiz A, Bernardo E, Alfonso F, Macaya C, Bass TA and Costa MA: Variability in individual responsiveness to clopidogrel: Clinical implications, management, and future perspectives. J Am Coll Cardiol 49: 1505-1516, 2007.

6. Wang TH, Bhatt DL and Topol EJ: Aspirin and clopidogrel resistance: An emerging clinical entity. Eur Heart J 27: 647-654, 2006.

7. Al-Azzam SI, Alzoubi KH, Khabour OF, Nusair MB Al-Hadidi H, Awidi A and Saleh A: Factors that contribute to clopidogrel resistance in cardiovascular disease patients: Environmental and genetic approach. Int J Clin Pharmacol Ther 51: 179-186, 2013.

8. Koh YY, Kim HH, Choi DH, Lee YM, Ki YJ, Kang SH, Park G, Chung JW, Chang KS and Hong SP: Relation between the change in mean platelet volume and clopidogrel resistance in patients undergoing percutaneous coronary intervention. Curr Vasc Pharmacol: 687-693, 2015.

9. Bliden KP, Dichiara J, Lawal L, Singla A, Antonino MJ, Baker BA, Bailey WL, Tantry US and Gurbel PA: The association of cigarette smoking with enhanced platelet inhibition by clopidogrel. J Am Coll Cardiol 52: 531-533, 2008.

10. Geiger J, Brich J,Hönig-LiedlP, Eigenthaler M, Schanzenbächer P, Herbert JM and Walter U: Specific impairment of human platelet P2Y(AC) ADP receptor-mediated signaling by the antiplatelet drug clopidogrel. Arterioscler Thromb Vasc Biol 19: 2007-2011, 1999.

11. Bonello L, Paganelli F, Arpin-Bornet M, Auquier P, Sampol J, Dignat-George F, Barragan P and Camoin-Jau L: Vasodilator-stimulated phosphoprotein phosphorylation analysis prior to percutaneous coronary intervention for exclusion of postprocedural major adverse cardiovascular events. J Thromb Haemost 5: 1630-1636, 2007.

12. Cotton JM, Worrall AM, Hobson AR, Smallwood A, Amoah V, Dunmore S, Nevill AM, Raghuraman RP, Vickers J and Curzen N: Individualised assessment of response to clopidogrel in patients presenting with acute coronary syndromes: A role for short thrombelastography? Cardiovasc Ther 28: 139-146, 2010. 
13. Nagalla S, Shaw C, Kong X, Kondkar AA, Edelstein LC, Ma L, Chen J, McKnight GS, López JA, Yang L, et al: Platelet microRNA-mRNA coexpression profiles correlate with platelet reactivity. Blood 117: 5189-5197, 2011.

14. Plé H, Landry P, Benham A, Coarfa C, Gunaratne PH and Provost P: The repertoire and features of human platelet microRNAs. PLoS One 7: e50746, 2012.

15. Duan X, Zhan Q, Song B, Zeng S, Zhou J, Long Y, Lu J, Li Z, Yuan M, Chen X, et al: Detection of platelet microRNA expression in patients with diabetes mellitus with or without ischemic stroke. J Diabetes Complications 28: 705-710, 2014.

16. Wang K, Yuan Y, Cho JH, McClarty S, Baxter D and Galas DJ: Comparing the MicroRNA spectrum between serum and plasma. PLoS One 7: e41561, 2012.

17. Landry P, Plante I, Ouellet DL, Perron MP, Rousseau G and Provost P: Existence of a microRNA pathway in anucleate platelets. Nat Struct Mol Biol 16: 961-966, 2009.

18. Kondkar AA, Bray MS, Leal SM, Nagalla S, Liu DJ, Jin Y, Dong JF, Ren Q, Whiteheart SW, Shaw C and Bray PF: VAMP8/endobrevin is overexpressed in hyperreactive human platelets: Suggested role for platelet microRNA. J Thromb Haemost 8: 369-378, 2010.

19. Girardot M, Pecquet C, Boukour S, Knoops L, Ferrant A, Vainchenker W, Giraudier S and Constantinescu SN: miR-28 is a thrombopoietin receptor targeting microRNA detected in a fraction of myeloproliferative neoplasm patient platelets. Blood 116: 437-445, 2010.

20. Aleil B, Ravanat C, Cazenave JP, Rochoux G, Heitz A and Gachet C: Flow cytometric analysis of intraplatelet VASP phosphorylation for the detection of clopidogrel resistance in patients with ischemic cardiovascular diseases. J Thromb Haemost 3: 85-92, 2005

21. Dweep H, Gretz N and Sticht C: miRWalk database for miRNA-target interactions. Methods Mol Biol 1182: 289-305, 2014.

22. Livak KJ and Schmittgen TD: Analysis of relative gene expression data using real-time quantitative PCR and the $2^{-\Delta \Delta C}$ method. Methods 25: 402-408, 2001.

23. Cuisset T, Frere C, Quilici J, Gaborit B, Castelli C, Poyet R, Bali L, Morange PE, Alessi MC and Bonnet JL: Predictive values of post-treatment adenosine diphosphate-induced aggregation and vasodilator-stimulated phosphoprotein index for stent thrombosis after acute coronary syndrome in clopidogrel-treated patients. Am J Cardiol 104: 1078-1082, 2009.
24. Nguyen TA, Diodati JG and Pharand C: Resistance to clopidogrel: A review of the evidence. J Am Coll Cardiol 45: 1157-1164, 2005

25. Spokoyny I, Barazangi N, Jaramillo V, Rose J, Chen C, Wong C and Tong D: Reduced clopidogrel metabolism in a multiethnic population: Prevalence and rates of recurrent cerebrovascular events. J Stroke Cerebrovasc Dis 23: 694-698, 2014.

26. Gurbel PA, Bliden KP, Hiatt B and O'Connor CM: Clopidogrel for coronary stenting: Response variability, drug resistance, and the effect of pretreatment platelet reactivity. Circulation 107: 2908-2913, 2003.

27. Jy W, Horstman LL, Park H, Mao WW, Valant P and Ahn YS: Platelet aggregates as markers of platelet activation: Characterization of flow cytometric method suitable for clinical applications. Am J Hematol 57: 33-42, 1988.

28. Satoh K, Yatomi Y and Ozaki Y: Detection method for platelet activation markers. Rinsho Byori 50: 773-778, 2002 (In Japanese).

29. Bonello L, Tantry US, Marcucci R, Blindt R, Angiolillo DJ, Becker R, Bhatt DL, Cattaneo M, Collet JP, Cuisset T, et al: Consensus and future directions on the definition of high on-treatment platelet reactivity to adenosine diphosphate. J Am Coll Cardiol 56: 919-933, 2010.

30. Morel O, Viellard C, Faure A, Jesel L, Ohlmann P, Desprez D, Chauvin M, Roul G, Grunebaum L and Bareiss P: Platelet responsiveness to clopidogrel in patients with coronary syndrome. Comparison of platelet aggregation induced by ADP and flow cytometric analysis of intraplatelet VASP phosphorylation. Ann Cardiol Angeiol (Paris) 56: 21-29, 2007 (In French)

31. Kim KA, Park PW, Hong SJ and Park JY: The effect of CYP2C19 polymorphism on the pharmacokinetics and pharmacodynamics of clopidogrel: A possible mechanism for clopidogrel resistance. Clin Pharmacol Ther 84: 236-242, 2008.

32. Notarangelo MF, Bontardelli F and Merlini PA: Genetic and nongenetic factors influencing the response to clopidogrel. J Cardiovasc Med (Hagerstown) 14 (Suppl 1): S1-S7, 2013.

33. Berezikov E, Cuppen E and Plasterk RH: Approaches to microRNA discovery. Nat Genet 38 (Suppl): S2-S7, 2006. 